\title{
Designing an accurate system for temperature measurements
}

\author{
Orest Kochan ${ }^{1, *}$, Jun $\mathrm{Su}^{2}$, and Roman Kochan ${ }^{1,3}$ \\ ${ }^{1}$ Lviv Polytechnic National University, Department of measuring information technologies, 79013 Karpinskoho Str. 1, Lviv, Ukraine \\ ${ }^{2}$ School of Computer Science, Hubei University of Technology, Wuhan, China \\ ${ }^{3}$ University of Bielsko-Biala, Bielsko-Biala, Poland
}

\begin{abstract}
The method of compensation of changes in temperature field along the legs of inhomogeneous thermocouple, which measures a temperature of an object, is considered in this paper. This compensation is achieved by stabilization of the temperature field along the thermocouple. Such stabilization does not allow the error due to acquired thermoelectric inhomogeneity to manifest itself. There is also proposed the design of the furnace to stabilize temperature field along the legs of the thermocouple which measures the temperature of an object. This furnace is not integrated with the thermocouple mentioned above, therefore it is possible to replace this thermocouple with a new one when it get its legs considerably inhomogeneous.. There is designed the two loop measuring system with the ability of error correction which can use simultaneously a usual thermocouple as well as a thermocouple with controlled profile of temperature field. The latter can be used as a reference sensor for the former.
\end{abstract}

\section{Introduction}

Technical progress is challenging for measurement technologies and instruments due to the constant improvement and complication of technological processes in industry. Measurement chains are necessary to component in production quality management, therefore the market of metrological services is important branch of economy in developed countries. It is estimated to be about $4 \%$ of GDP $[1,2]$.

The concept of temperature as well as phenomena and techniques on which temperature measurements are based, evolved together with the development of science. The measuring instrument by which the temperature of bodies is measured is called a thermometer. The branch of science connected with construction and usage of thermometers is called thermometry $[3,4]$. The history of thermometry is an important part of history of science [5]. The first ideas about heat and temperature appeared long time ago, but Empedocles and Aristotle are the first scientists whose works are now known. Therefore they are considered as early founders of thermal science. Almost two thousand years after these two Galilei and most prominent scientists of the XVII century including Hooke, Von Guericke, Boyle, Huygens, Newton and many others contributed to the concept of temperature and its measurement [6]. Their works became the theoretical base for practical temperature scales invented in the XVIII century by Fahrenheit, Celsius, Romer, Reaumur and others. Some of these scales survived till now and are widely used in modern praxis. These ideas of thermometers and scales were based on common sense and practical needs but not on deep theoretical notions. Therefore constructions of thermometers as well as temperature units varied considerably.

Explosive development of industry during the XVIII-XIX centuries is now known as the Industrial Revolution [7] required accurate and reliable techniques of temperature measurements. Development of thermodynamics allowed physics to develop deep theoretical notions of temperature and heat. There was possible to adjust existing temperature scales using explanations of thermal behavior of matter. The newly developed theory of thermodynamics led to the concept of absolute thermodynamic temperature introduced by William Thomson (Lord Kelvin) [8]. This concept is based on the Carnot cycle and fundamental thermodynamic laws. According to modern understanding, temperature is a quantitative expression of the average kinetic energy contained in a piece of matter $[8,9]$. This is the most familiar definition. In general, for any substance, the higher the temperature, the faster its atoms or molecules move.

The unit of thermodynamic temperature, (also often referred to as Kelvin temperature or absolute temperature), is kelvin $(\mathrm{K})$ and is defined in terms of the interval between the absolute zero of temperature and the triple point of pure water $(273.16 \mathrm{~K})$. One kelvin is the fraction $1 / 273.16$ of that temperature interval. In addition to the thermodynamic temperature, the Celsius $\left({ }^{\circ} \mathrm{C}\right)$ temperature scale is

\footnotetext{
Corresponding author: orestvk@gmail.com
} 
used in everyday life. The Celsius temperature is defined as equal to the thermodynamic temperature minus 273.15 whereas the Celsius degree $\left(1^{\circ} \mathrm{C}\right)$ is numerically equal to that of Kelvin.

Intensification of international trade and collaboration led to the need for accurate measurements using unified instruments and practical realization of temperature scale which could be internationally recognized. Therefore, after long negotiations and discussions, there was established the International Bureau of Weights and Measures (IBWM) in 1875. Thermometry was in focus of interest of the IBWM since its establishment but as an auxiliary measure required for measurement of the temperature of accurate standards of length. Difficulties with measurement reproducibility led to the need of unification of temperature scales for the sake of accurate measurements of temperatures and subsequently to the promotion of temperature to a main physical quantity along with length, mass and other quantities. The studies of gas thermometers carried out by P. Chappuis [10] are now considered as the origin of modern thermometry. Based on these studies, the normal hydrogen scale was established in 1887. The main drawback of this thermometer was the approximation of the ideal gas with hydrogen therefore the scale deviated from the thermodynamic temperature. A competing sensor - the resistance temperature detector appeared in this time invented and researched by Callendar [11]. Later this invention played a very important role in the thermometry because this invention became a base of later temperature scales due to its convenience in practical use. The period between 1887 and 1927 was dedicated to the study of a more convenient temperature scale [12]. The new scale was adopted in 1927 under the title "the International Temperature Scale of 1927" [12]. This scale was replaced by the one adopted in 1948 under the title "the International Practical Temperature Scale 1948" [12]. It was amended and extended toward low temperatures in 1968. The new version got the title "the International Practical Temperature Scale 1968" [12]. The next step was made in 1990 when a new temperature scale came into action. Its title is "the International Practical Temperature Scale 1990" [12, 13]. This scale together with the Provisional Low Temperature Scale of 2000 are valid now [12]. They are based on a set of fixed points and are split into a number of overlapping ranges and sub-ranges; [12, 13]. Nowadays temperature is one of the most frequently measured physical quantities. The accuracy of temperature measurements often directly determines the quality, effectiveness and safety of industrial manufacturing processes [14-18]. According to [4]: "Statistical data show that the percentage of temperature measurements is $40 \%$ of all measurements in industry. In some branches of industry this percentage may be even considerably higher, in particular in power industry it equals about
$70 \%$." That is why so many methods, techniques and sensors for temperature measurements exist [3, 4].

The expansion of the sphere of temperature measurements $[3,4,18-20]$, the increase in the requirements for their quality $[17,21]$ and the need for non-stationary measurements $[15,18,19]$ imposes additional requirements on sensors [1, 4, $22]$, equipment [23, 24] and methods of signal processing $[20,21]$.

\section{Thermocouples}

However, despite the variety of existing sensors, thermocouples (TC) dominate in measurement praxis $[3,4]$. Base metal TCs are the most popular TCs. Noble metal TCs dominate among the standard instruments whereas refractory metal TCs are used for high temperatures (above $1300^{\circ} \mathrm{C}$ ) $[3,4]$.

The phenomenon of thermoelectricity, that is what the thermocouple is based on, was discovered in 1821 by Seebeck [25]. The first attempt to measure temperature using thermocouples was made in 1826 by A. C. Becquerel. He also discovered that the Seebeck's coefficient does not depend on the wire diameter and length [25]. However, due to lack of accurate and sensitive instruments, the thermocouple was not popular because its electromotive force (emf) vs temperature dependence was not accurately determined. In addition, it was found that either small contamination or permanent strain in thermocouple (TC) legs considerably alter the emf vs temperature dependence [25]. The practical needs of the cement manufacture industry led to studies in the field of high temperature measurements using thermocouples carried out by Le Chatelier [26]. Due to his efforts the thermocouple became an accurate and reliable temperature sensor. It was spread throughout the World very fast and adopted in other branches of industry, e.g. metallurgy [25]. By this time, all TCs were made of noble metals and their alloys, however in the beginning of the XX century appeared much cheaper and more suitable for practical use base metal TCs [27]. One of them, the type K TC, is now the most widely used temperature sensor.

The merits of TCs are: (i) wide range of measurements [3, 4], (ii) simple design, [3, 4], (iii) low price [28]. However, there is one considerable drawback such as degradation of TC legs $[22,29,30]$. Degradation processes are prone to all types of used TCs [31-37]. They appear due to long term use at high temperatures [29,36]. According to [22], the degradation of TC legs leads to two interrelated errors: (i) the error due to the change in the developed emf with time in a constant temperature field along TC legs. It is referred to as the error due to drift of a conversion characteristic (CC) of a TC $[34,38,39]$; (ii) the error due to the change in the developed thermal emf in a changeable temperature field along TC legs. It is referred to as the error due 
to thermoelectric inhomogeneity of TC legs acquired during operation $[22,30,37,40-42]$.

For the first time, the problem of thermoelectric inhomogeneity was considered in 1906 [43], but according to $[29,30,32,44]$ it still remains one of the main sources of error in temperature measurements using TC. Despite the studies in this field $[40,42,44-$ 47] the problem has still not been solved yet. Thermoelectric inhomogeneity is considered to be the main source of TC error [30,43]

The ways to increase the accuracy of temperature measurements by TCs with significant acquired during long-term operation thermoelectric inhomogeneity of legs were proposed in the paper [48]. The method of correction of this error was considered and studied in the paper [49]. However, the efficiency of the method [49] decreases with the change in the nature of drift of CC of TC sections as a consequence of a change in the temperature field. This occurs for long-term changes of a temperature field, when temperatures of TC sections after the change in the temperature field, will be perceived by these TC sections as new operating temperatures. In this case the method of compensation of changes in the temperature field along the legs of the TC which measures the temperature of an object $[48,50]$ is more effective. The method is based on one of the fundamental properties of the inhomogeneity [22] if there is no change in the profile of a temperature field along TC legs, then their acquired inhomogeneity, no matter how large it is, can neither manifest itself nor cause error of temperature measurements. In this case, the degradation processes running in $\mathrm{TC}$ legs will manifest themselves exclusively as the drift of the TC CC with time. Thus, all the methods for drift correction mentioned in [48] are fully suitable for effective improvement of the measurement accuracy. Generally speaking, the error due to acquired inhomogeneity of TC legs is the error of a random nature with respect to the operation time (it corresponds to random changes in the temperature field along TC legs). This error in a constant temperature field converts into a systematic error of the drift of the TC CC with time, which in turn can be corrected. The correction methods listed in point 2 of paper [48] are considered in [51-52]. They can use results of a calibration either in a calibration laboratory [51], or in situ [53,54].

The goal of the paper is to develop the method which will counteract the manifestation of the error due to acquired thermoelectric inhomogeneity of TC legs in a changeable temperature field of operation.

\section{The method of compensation of the error due to acquired thermoelectric inhomogeneity of TC legs}

It is necessary to stabilize the profile of a temperature field along the legs of the TC, which measures the temperature of an object, to implement the method of compensation of the effect of acquired inhomogeneity of TC legs proposed in $[48,50]$. The stabilization can be achieved by creating an independent temperature field for the TC, measuring the temperature of the object (the main thermocouple), by means of auxiliary temperature control systems. The heaters and sensors of these systems should be located coaxially with the main thermocouple (MTC) and must be shifted along the axis of the MTC legs. The structure of the proposed TC with controlled profile of temperature field (TCPTF) is shown in Fig. 1 [50].

The TCPTF consists of: (i) the main thermocouple (MTC), whose goal is to measure the temperature of an object; (ii) the subsystems to control the temperature field are along the legs of the MTC. Each subsystem consists of a heater (H1...Hn) and a corresponding thermocouple (TC1...TCn). All TCs have their reference junctions wired to a measuring and controlling system (MCS). In the bottom part of Fig. 1 there is shown the temperature field ABC. This field is established and maintained by the heaters H1..Hn. Therefore, even if the object's temperature field changes within the fields E...F, the field ABC remains stable and constant. This prevents the manifestation of the error due to acquired inhomogeneity of the MTC. Therefore the methods of correction for the error due to acquired inhomogeneity can be used on the objects with changeable temperature field, because the proposed TCPTF maintains its own stable temperature field.

\section{The furnace with controlled profile of temperature field}

The design of TCPTF proposed in [50], presented in Fig. 1.

If the TCPTF is made as an integrated sensor, it has significant drawbacks: (i) lack of unification with existing TCs due to complexity and uniqueness of the design; (ii) impossibility of using already produced TCs; (iii) difficulties with replacement of the MTC when it get its legs significantly degraded (inhomogeneous); (iv) the need for metrological certification as a new type of sensor. These drawbacks are significant as they hamper implementation of the TCPTF. However, these drawbacks are not prone to the method of compensation of the effect of changes in the temperature field of the object on the temperature field of the MTC. They are only prone to the design of the TCPTF as an integrated sensor.

To eliminate them, it is reasonable to split the TCPTF [55,56] into: (i) the MTC itself. As a MTC it is reasonable to use a usual TC. (ii) the mean for stabilizing the temperature field (the special furnace) along the legs of the usual TC mentioned in point 1 .

One of the problems in creating such a special furnace is the need to bring a large number of leadouts to the butt of the furnace. For instance, for 10section furnace it is necessary to place 40 lead-outs, 
insulated by ceramic beads due to high temperature, on the butt of the furnace. The main idea is to combine a heater and a TC that measures the temperature of a section by making a heater from one thermocouple material, and its lead-out from the complementary one. This allows reducing the number of lead-outs,

A structure of the special furnace proposed in $[55,56]$ is shown in Fig. 2. It consists of the outer 1 and inner 2 tubular shells (the diameter of the inner thermal inertia. This happens because of the need to wait until the end of the transient processes, not only for the measuring junction of the MTC, but also to stabilize the entire present temperature field along the legs of the MTC to get measurement results without the influence of the error due to the acquired thermoelectric inhomogeneity of the MTC.

The time of such stabilization, taking into account the thermal connection between sections of the TCPTF, can, in the worst case, exceed $2 \ldots 3$

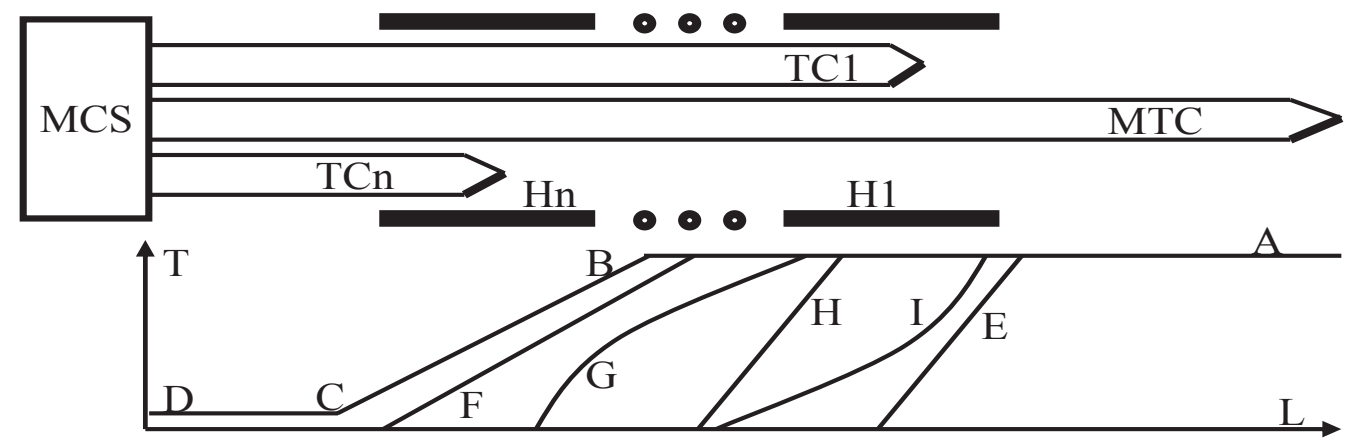

Fig. 1. Block diagram of the proposed TCPTF [47, 49].

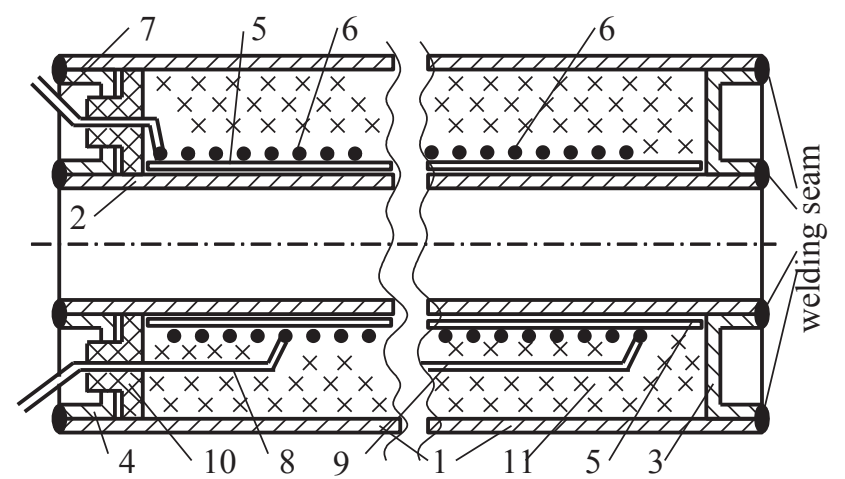

Fig. 2. Structure of a special furnace.

case corresponds to the outer diameter of a usual TC thermowell). Shells 1 and 2 are welded together by walls 3 and 4 . There is an insulating (ceramic) cylinder 5 inside of the furnace. Heater 6 is either wounded or sprayed on cylinder 5 . Terminals $7 \ldots 9$ of heater 6 are led out through insulating sleeves 10 . The space between shells 1 and 2 is filled with thermal insulation 11 .

The heaters and TCs are combined by making heater 6 and one of the outermost lead out 7 , for instance from chromel, and the other lead outs ( 8 and 9) from the complementary TC material alumel. In this case, the heater together with the lead outs form the chromel-alumel TCs, or in other words, type $\mathrm{K}$ TCs. With 10 sections of heaters, the number of lead outs (sleeves 10) will be $11[55,56]$.

\section{The structure of the system using the TCPTF}

The direct use of the TCPTF for temperature measurement is hampered by its considerable hours. Such a time can cause additional dynamic errors when measuring temperature of large objects. Such a time constant is inappropriate with the use of TCPTF in control systems. Therefore, it is proposed to add the error correction circuit equipped with a usual TC of the usual inertial properties to a measuring chain, based on a TCPTF.

The structure of such a two-loop control system is shown in Fig. 3. It consists of a TCPTF and its measuring chain $\mathrm{MC} 1$, a usual $\mathrm{TC}$ and its measuring chain MC2, the correction unit CORR, the adder AD, the set unit establishing the temperature to maintain SET, the regulator REG, and the heater of an object HEAT. The loop TC - MC2 - AD - REG - HEAT works as a normal control system and implements any of the known laws of control (P, PI, PID). The measuring junctions of the TC and the TCPTF are located closely to each other so that there is virtually no temperature difference between them on a particular object.

The TCPTF, its measuring chain MC1 and the correction unit CORR form a correction channel that compares the results of measurements carried out by the TC with that of carried out by the TCPTF. It quite rarely (for example, when the change of a temperature field of the object exceeds the permissible value, but not less than once a day) corrects the TC error by submitting the appropriate correction signal to the adder AD. In this case, the correction signal can be obtained practically without a time limit for its formation.

Thus, the dynamic properties of the control system will not differ from that of traditional systems that use usual TCs. 


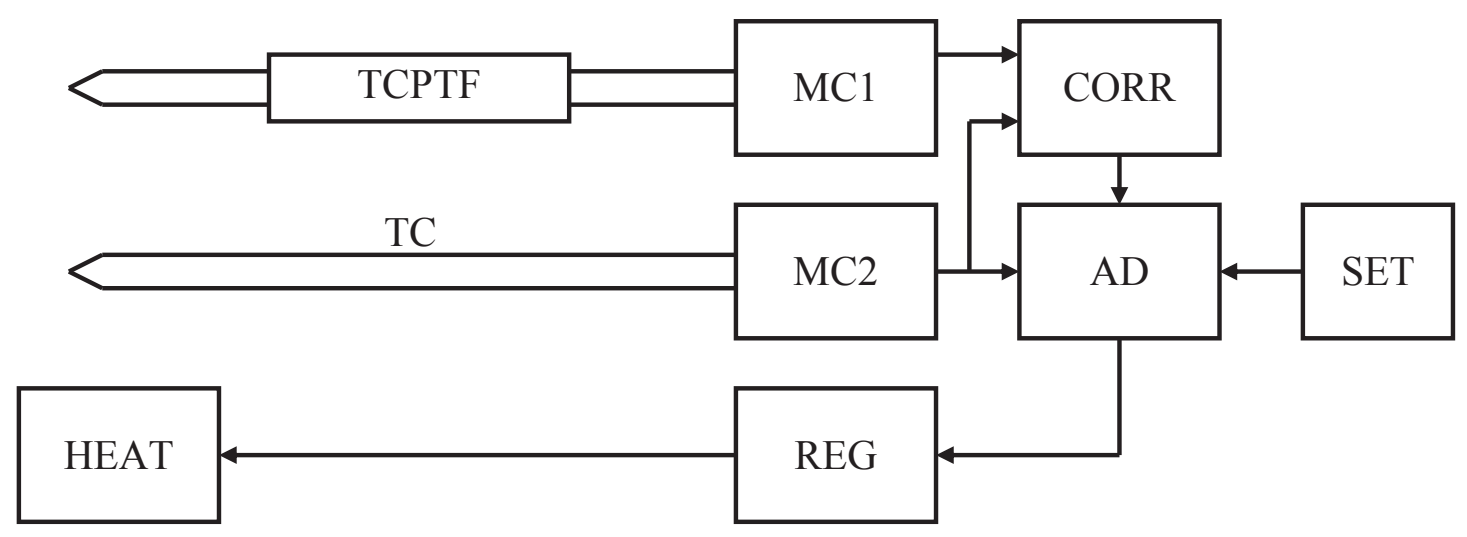

Fig. 3. The structure of the two-loop control system using a TCPTF.

\section{Conclusions}

The proposed method for compensating changes in a temperature field along the legs of a TC measuring the temperature of an object has a rather high efficiency. In contrast to the method of correction of the error due to acquired thermoelectric inhomogeneity considered in [48], this method does not correct the error due to drift a TC CC. However, it makes it possible to apply the known methods of correction of the error due to drift of a TC CC listed in [47], generalized in [50] and developed in [51]. In this case, in contrast to the correction method [48], the considered method of compensation creates almost ideal conditions for the use of the methods for correcting the error due to drift of TC C, because all sections of a TC under any changes in the temperature field of the object, remain at the temperature of constant operation. There is also no danger of changing the character of the error due to drift of a TC CC (or its sections) and the associated danger of an increasing the residual error of correction. These advantages determine the prospects of the proposed method.

The proposed is designed for objects where high accuracy of measurement is important either from the safety point of view or from the economical point of view. For instance, improved accuracy of temperature measurements in thermal power plants can save 400 million US dollars worldwide a year [57]. The direction of further studies lies in modelling using the metrological software test [58] to study errors of the whole proposed system or its main components.

This work was supported by Foundation of Wuhan Science and technology Bureau (2015030809020370), Doctoral Scientific Research Fund from Hubei University of Technology (No. BSQD14037), National Natural Science Foundation of China (Nos. 61602162, 61502155), Green Industry Technology Leading Project of Hubei University of Technology (No. ZZTS2016004).

\section{References}

1. J. Birch, Benefit of Legal Metrology for the Economy and Society. (A study for the International Committee of Legal Metrology, 2003) https://www.oiml.org/en/files/pdf_e/e002e03.pdf

2. J. Birch, Role and impact of legal metrology for consumer protection. (ISO/COPOLCO Workshop, 2012) http://www .iso.org/iso/livelinkgetfile?1lNodeId= $400882 \& 11$ VolId $=-2000$

3. J. Webster, Measurement, Instrumentation, and Sensors Handbook (CRCnetBase, 1999)

4. Y. Lutsyk, O. Hook, O. Lakh, B. Stadnyk, Temperature Measurements: Theory and Praxis (Lviv, 2006) (In Ukrainian)

5. F. Sherwood Taylor, 5(2), 129-156 (1942)

6. H. Chang. Inventing Temperature: Measurement and Scientific Progress (Oxford, 2004)

7. $\mathrm{R}$ Allen. The British Industrial Revolution in Global Perspective (Cambridge and New York, 2009)

8. R. Wolfson. Essential University Physics, 2nd Edition (Middlebury College, 2012)

9. S. Gibilisco. Physics demystified. (New York, 2002)

10. P. Chappuis. Trav. Mem. Bur. Int. Poids Mes. VI, 1-19 (1888)

11. H. L. Callendar. Philos. Mag. 34, 104-111 (1891)

12. http://www.bipm.org/en/measurementunits/history-si/temperature-scales/

13. H. Preston-Thomas. Metrologia 27, 3-10 (1990)

14. H. R. Ashrafi, K. Shahbazian, S. Bidmeshki, S. Yaghooti, P. Beiranvand. Adv. Sci. Technol. Res. J. 10, 29, 1-12 (2016)

15. V. Perzel, M. Flimel, J. Krolczyk, A. Sedmak, A. Ruggiero, D. Kozak, A. Stoic, G. Krolczyk, S. Hloch, Thermal Sci. 00, 46 (2016) DOI: 10.2298/TSCI150212046P

16. A. Glowacz, A. Glowacz, Z. Glowacz, Meas. Sci. Rev. 15, 3, 119-126 (2015) 
17. R. W. Maruda, G. M. Krolczyk, E. Feldshtein, F. Pusavec, M. Szydlowski, S. Legutko, A. Sobczak-Kupiec, Int. J. Mach. Tool. Manu. 100, 81-92 (2016)

18. T. Habisreuther, T. Elsmann, Z. Pan, A. Graf, R. Willsch, M.A. Schmidt. Appl. Therm. Eng. 91, 860-865 (2015).

19. P. Hreha, A. Radvanska, L. Knapcikova, G.M. Krolczyk, S. Legutko, J.B. Krolczyk, S. Hloch, P. Monka. Metrol. Meas. Syst. 22, 315-326 (2015)

20. A. Glowacz, A. Glowacz, P. Korohoda, Arch. Metall. 59(1), 31-34 (2014)

21. A. Glowacz, Z. Glowacz, Measurement 93, 8693(2016)

22. J. Su, O. Kochan, Meas. Tech+ 57,10, 11601166 (2015)

23. A. Aly, A. El-Lail, I.J. Information Technology and Computer Science, 03, 56-60 (2013)

24. R. Kochan, O. Berezky, A. Karachka, O. Bojko, I. Maruschak, IEEE T. Instrum. Meas. 51(1), 96101 (2002)

25. L. B. Hunt, Plat. Metals Rev. 8, 23-28 (1964)

26. H. Le Chatelier, Compt. rend. 102, 819-826, (1886)

27. I. A. Rogelberg, V. M. Beylin, Alloys for thermocouples: Reference book (Moscow, 1983)

28. P. R. N. Childs, J. R. Greenwood, C. A. Long, Rev. of Sci. Instrum. 71, 2959- 2978 (2000)

29. K. C. Sloneker, Ceram. Ind. 159(4), 13-18 (2009).

30. D.J. Southworth, Temperature Calibration with Isotech Block Baths (Southport, Isotermal technology ltd, 1999)

31. R. M. Park, Manual on the use of thermocouples in temperature measurement (ASTM, New York, 1993)

32. Y. Abdelaziz, F. Edler, Meas. Sci. Technol., 20(5), 055102, (2009) doi:10.1088/09570233/20/5/055102

33. J. V. Pearce, Meas. Sci. Technol. 18, 11 34893495 (2007)

34. R. Strnad, M. Jelínek, G. Failleau, T. Deuzé, M. Sadli, N. Arifovic, A. Diril, P. Pavlasek, M. Langley, J. V. Pearce, Automa. 6, 28-31 (2014)

35. T. J. Quinn, Temperature (London, 1983)

36. V. P. Pavlov, Thermoelectric inhomogeneity of thermocouple legs (Publishing House of Standards, Moscow, 1979)

37. M. Holmsten, J. Ivarsson, R. Falk, M. Lidbeck, L.-E. Josefson, Int. J Thermophys. 29(3), 915925 (2008)

38. L. Kortvelyessy, Thermoelement praxis (VulkanVerlag, Essen, 1981)

39. N. Rogelberg, A. Nuzhnov, G. Pokrovskaya et all, Investigation of alloys for thermocouples (Metallurgiya, Moscow) 29, 33-41 (1969)

40. J. Tamba, K. Yamazawa, S. Masuyama, H. Ogura, M. Izuchi, Int. J. Thermophys. 32, 2436$2451(2011)$
41. E. S. Webster, D. R. White, H. Edgar, Int. J. Thermophys. 36, 444-466, (2015)

42. M. Hiti, J. Bojkovski, V. Batagelj, J. Drnovšek, Elektrotehniški vestnik/Electrotechnical Review. 72, 4, 189-194 (2005)

43. W. P. White, Phys. Rev. 23, 4, 449-474 (1906)

44. M. Holmsten, S. Ljungblad, L. E. Josefson, IProc. of the int. Symposium TEMPMEKO. Portorož (Slovenia), A, 87 (2010)

45. Y.G. Kim, K.S. Gam, J.H. Lee, Meas. Sci. Technol. 8, 317-321 (1997)

46. K. D. Hill, D. J. Gee, Proc. of the 9-th int. temperature symposium temperature: its measurement and control in science and industry, Los Angeles, (USA), 8(1552), 520-525 (2012)

47. G. Zaid, Instrumentasi 27, 1, 18-21 (2003)

48. J. Su, O. V. Kochan, V. S. Jotsov, Meas. Tech+. 58, 3, 327-330 (2015)

49. Jun Su, O. Kochan, N. Vasylkiv, R. Kochan, Meas. Tech+, 58, 8, 904-910 (2015)

50. O. Kochan, R. Kochan, O. Bojko, M. Chyrka, Proc. of the 4th IEEE International Workshop IDAACS'2007, Dortmund, Germany. 47-51 (2007)

51. A. Sachenko, Accuracy increasing methods development and precision measurement system design for industry. Dissertation abstract fo the doctor of engineering degree (Leningrad, 1988)

52. A. Sachenko, V. Kochan, V. Turchenko, V. Holovko, Y. Savitski, T. Laopoulos, Patent of Ukraine №50830.

53. G. Failleau, C. J. Elliott, T. Deuzé, J. V. Pearce, G. Machin, M. Sadli, Int. J. Thermophys. 35, 1223-1238 (2014)

54. D. Zvizdic, D. Sestan, Int. J. Thermophys. 36, 336-346 (2015)

55. O. Kochan, J. Su, V. Kochan, Proc. of the 13th IMEKO TC10 Workshop on technical diagnostics advanced measurement tools in technical diagnostics for systems' reliability and safety Warsaw (Poland), 105-110 (2014)

56. J. Su, O. Kochan, V. Kochan, Chunzhi Wang, Int. J Thermophys. 37, 10 (2016) DOI 10.1007/s 10765-015-2025-x

57. T. Wang, D. Bediones, P. Swirla, H. Henrikson, E. Janhunen, K. Bachalo, Stabilized metal sheathed type $\mathrm{K}$ and $\mathrm{E}$ thermocouples improve turbine efficiency. ISA, 439-448, (1997)

58. Kochan R, Proc. of the 2nd IEEE international workshop of IDAACS'2003, 168 - 173 (2003). 